\title{
Participating Life Insurance Contracts under Risk Based Solvency Frameworks: How to Increase Capital Efficiency by Product Design
}

\author{
Andreas Reuß, Jochen Ruß and Jochen Wieland
}

\begin{abstract}
Traditional participating life insurance contracts with year-to-year (cliquet-style) guarantees have come under pressure in the current situation of low interest rates and volatile capital markets, in particular when priced in a market consistent valuation framework. In addition, such guarantees lead to rather high capital requirements under risk-based solvency frameworks such as Solvency II or the Swiss Solvency Test (SST). We introduce several alternative product designs and analyze their impact on the insurer's financial situation. We also introduce a measure for Capital Efficiency that considers both, profits and capital requirements, and compare the results of the innovative products to the traditional product design with respect to Capital Efficiency in a market consistent valuation model.
\end{abstract}

Keywords Capital efficiency - Participating life insurance $\cdot$ Embedded options • Interest rate guarantees - Market consistent valuation $\cdot$ Risk based capital requirements $\cdot$ Solvency II $\cdot \mathrm{SST}$

\section{Introduction}

Traditional participating life insurance products play a major role in old-age provision in Continental Europe and in many other countries. These products typically come with a guaranteed benefit at maturity, which is calculated using some guaranteed minimum interest rate. Furthermore, the policyholders receive an annual surplus participation that depends on the performance of the insurer's assets. With the so-

\footnotetext{
A. Reuß

Institut für Finanz- und Aktuarwissenschaften, Lise-Meitner-Straße 14, 89081 Ulm, Germany e-mail: a.reuss@ifa-ulm.de

J. Ruß J J. Wieland $(\bowtie)$

Institut für Finanz- und Aktuarwissenschaften, Ulm University, Lise-Meitner-Straße 14, 89081 Ulm, Germany

e-mail: j.russ@ifa-ulm.de

J. Wieland

e-mail: j.wieland@ifa-ulm.de

(C) The Author(s) 2015

K. Glau et al. (eds.), Innovations in Quantitative Risk Management,

Springer Proceedings in Mathematics \& Statistics 99,

DOI 10.1007/978-3-319-09114-3_11
} 
called cliquet-style guarantees, once such surplus has been assigned to the policy at the end of the year, it increases the guaranteed benefit based on the same guaranteed minimum interest rate. This product design can create significant financial risk.

Briys and de Varenne [8] were among the first to analyze the impact of interest rate guarantees on the insurer's risk exposure. However, they considered a simple pointto-point guarantee where surplus (if any) is credited at maturity only. The financial risks of cliquet-style guarantee products have later been investigated, e.g., by Grosen and Jorgensen [17]. They introduce the "average interest principle", where the insurer aims to smooth future bonus distributions by using a bonus reserve as an additional buffer besides the policy reserve (the client's account). Besides valuing the contract they also calculate default probabilities (however, under the risk-neutral probability measure $\mathbb{Q}$ ). Grosen et al. [19] extend the model of Grosen and Jorgensen [17], and introduce mortality risk. Grosen and Jorgensen [18] modify the model used by Briys and de Varenne [8] by incorporating a regulatory constraint for the insurer's assets and analyzing the consequences for the insurer's risk policy. Mitersen and Persson [23] analyze a different cliquet-style guarantee framework with the so-called terminal bonuses, whereas Bauer et al. [4] specifically investigate the valuation of participating contracts under the German regulatory framework.

While all this work focuses on the risk-neutral valuation of life insurance contracts (sometimes referred to as "financial approach"), Kling et al. [20, 21] concentrate on the risk a contract imposes on the insurer (sometimes referred to as "actuarial approach") by means of shortfall probabilities under the real-world probability measure $\mathbb{P}$.

Barbarin and Devolder [3] introduce a methodology that allows for combining the financial and actuarial approach. They consider a contract similar to Briys and de Varenne [8] with a point-to-point guarantee and terminal surplus participation. To integrate both approaches, they use a two-step method of pricing life insurance contracts: First, they determine a guaranteed interest rate such that certain regulatory requirements are satisfied, using value at risk and expected shortfall risk measures. Second, to obtain fair contracts, they use risk-neutral valuation and adjust the participation in terminal surplus accordingly. Based on this methodology, Gatzert and Kling [14] investigate parameter combinations that yield fair contracts and analyze the risk implied by fair contracts for various contract designs. Gatzert [13] extends this approach by introducing the concept of "risk pricing" using the "fair value of default" to determine contracts with the same risk exposure. Graf et al. [16] (also building on Barbarin and Devolder [3]) derive the risk minimizing asset allocation for fair contracts using different risk measures like the shortfall probability or the relative expected shortfall.

Under risk-based solvency frameworks such as Solvency II or the Swiss Solvency Test (SST), the risk analysis of interest rate guarantees becomes even more important. Under these frameworks, capital requirement is derived from a market consistent valuation considering the insurer's risk. This risk is particularly high for long term contracts with a year-to-year guarantee based on a fixed (i.e., not path dependent) guaranteed interest rate. Measuring and analyzing the financial risk in relation to the required capital, and analyzing new risk figures such as the Time Value of Options 
and Guarantees (TVOG) is a relatively new aspect, which gains importance with new solvability frameworks, e.g., the largest German insurance company (Allianz) announced in a press conference on June $25,2013^{1}$ the introduction of a new participating life insurance product that (among other features) fundamentally modifies the type of interest rate guarantee (similar to what we propose in the remainder of this paper). It was stressed that the TVOG is significantly reduced for the new product. Also, it was mentioned that the increase of the TVOG resulting from an interest rate shock (i.e., the solvency capital requirement for interest rate risk) is reduced by $80 \%$ when compared to the previous product. This is consistent with the findings of this paper.

The aim of this paper is a comprehensive risk analysis of different contract designs for participating life insurance products. Currently, there is an ongoing discussion, whether and how models assessing the insurer's risk should be modified to reduce the capital requirements (e.g., by applying an "ultimate forward rate" set by the regulator). We will in contrast analyze how (for a given model) the insurer's risk, and hence capital requirement can be influenced by product design. Since traditional cliquetstyle participating life insurance products lead to very high capital requirements, we will introduce alternative contract designs with modified types of guarantees, which reduce the insurer's risk and profit volatility, and therefore also the capital requirements under risk-based solvency frameworks. In order to compare different product designs from an insurer's perspective, we develop and discuss the concept of Capital Efficiency, which relates profit to capital requirements. ${ }^{2}$ We identify the key drivers of Capital Efficiency, which are then used in our analyses to assess different product designs.

The remainder of this paper is structured as follows:

In Sect.2, we present three considered contract designs that all come with the same level of guaranteed maturity benefit but with different types of guarantee:

- Traditional product: a traditional contract with a cliquet-style guarantee based on a guaranteed interest rate $>0$.

- Alternative product 1: a contract with the same guaranteed maturity benefit, which is, however, valid only at maturity; additionally, there is a $0 \%$ year-to-year guarantee on the account value meaning that the account value cannot decrease from one year to the next.

- Alternative product 2: a contract with the same guaranteed maturity benefit that is, however, valid only at maturity; there is no year-to-year guarantee on the account value meaning that the account value may decrease in some years.

\footnotetext{
${ }^{1}$ Cf. [1], particularly slide D24.

${ }^{2}$ Of course, there already exist other well-established measures linking profit to required capital, such as the return on risk-adjusted capital (RORAC). However, they may not be suitable to assess products with long-term guarantees since they consider the required capital on a one-year basis only. To the best of our knowledge there is no common measure similar to what we define as Capital Efficiency that relates the profitability of an insurance contract to the risk it generates, and hence capital it requires over the whole contract term.
} 
On top of the different types of guarantees, all three products include a surplus participation depending on the insurer's return on assets. Our model is based on the surplus participation requirements given by German regulation. That means in particular that each year at least $90 \%$ of the (book value) investment return has to be distributed to the policyholders.

To illustrate the mechanics, we will first analyze the different products under different deterministic scenarios. This shows the differences in product design and how they affect the insurer's risk.

In Sect. 3, we introduce our stochastic model, which is based on a standard financial market model: The stock return and short rate processes are modeled using a correlated Black-Scholes and Vasicek model. ${ }^{3}$ We then describe how the evolution of the insurance portfolio and the insurer's balance sheet are simulated in our asset-liability-model. The considered asset allocation consists of bonds with different maturities and stocks. The model also incorporates management rules as well as typical intertemporal risk sharing mechanisms (e.g., building and dissolving unrealized gains and losses), which are an integral part of participating contracts in many countries and should therefore not be neglected.

Furthermore, we introduce a measure for Capital Efficiency based on currently discussed solvency regulations such as the Solvency II framework. We also propose a more tractable measure for an assessment of the key drivers of Capital Efficiency.

In Sect. 4, we present the numerical results. We show that the alternative products are significantly more capital efficient: financial risk, and therefore also capital requirement is significantly reduced, although in most scenarios all products provide the same maturity benefit to the policyholder. ${ }^{4}$ We observe that the typical "asymmetry", i.e., particularly the heavy left tail of the insurer's profit distribution is reduced by the modified products. This leads to a significant reduction of both, the TVOG and the solvency capital requirement for interest rate risk.

Section 5 concludes and provides an outlook for further research.

\section{Considered Products}

In this section, we describe the three different considered contract designs. Note that for the sake of simplicity, we assume that in case of death in year $t$, always only the current account value $A V_{t}$ (defined below) is paid at the end of year $t$. This allows us to ignore mortality for the calculation of premiums and actuarial reserves.

\footnotetext{
${ }^{3}$ The correlated Black-Scholes and Vasicek model is applied in Zaglauer and Bauer [29] and Bauer et al. [5] in a similar way.

${ }^{4}$ Note: In scenarios where the products' maturity benefits do differ, the difference is limited since the guaranteed maturity benefit (which is the same for all three products) is a lower bound for the maturity benefit.
} 


\subsection{The Traditional Product}

First, we consider a traditional participating life insurance contract with a cliquetstyle guarantee. It provides a guaranteed benefit $G$ at maturity $T$ based on annual premium payments $P$. The pricing is based on a constant guaranteed interest rate $i$ and reflects annual charges $c_{t}$. The actuarial principle of equivalence ${ }^{5}$ yields

$$
\sum_{t=0}^{T-1}\left(P-c_{t}\right) \cdot(1+i)^{T-t}=G .
$$

During the lifetime of the contract, the insurer has to build up sufficient (prospective) actuarial reserves $A R_{t}$ for the guaranteed benefit based on the same constant interest rate $i$ :

$$
A R_{t}=G \cdot\left(\frac{1}{1+i}\right)^{T-t}-\sum_{k=t}^{T-1}\left(P-c_{k}\right) \cdot\left(\frac{1}{1+i}\right)^{k-t}
$$

The development of the actuarial reserves is then given by:

$$
A R_{t}=\left(A R_{t-1}+P-c_{t-1}\right) \cdot(1+i)
$$

Traditional participating life insurance contracts typically include an annual surplus participation that depends on the performance of the insurer's assets. For example, German regulation requires that at least a "minimum participation" of $p=90 \%$ of the (local GAAP book value) earnings on the insurer's assets has to be credited to the policyholders' accounts. For the traditional product, any surplus assigned to a contract immediately increases the guaranteed benefit based on the same interest rate $i$. More precisely, the surplus $s_{t}$ is credited to a bonus reserve account $B R_{t}$ (where $B R_{0}=0$ ) and the interest rate $i$ will also apply each year on the bonus reserve:

$$
B R_{t}=B R_{t-1} \cdot(1+i)+s_{t} .
$$

The client's account value $A V_{t}$ consists of the sum of the actuarial reserve $A R_{t}$ and the bonus reserve $B R_{t}$; the maturity benefit is equal to $A V_{T}$.

As a consequence, each year at least the rate $i$ has to be credited to the contracts. The resulting optionality is often referred to as asymmetry: If the asset return is above $i$, a large part (e.g., $p=90 \%$ ) of the return is credited to the client as a surplus and the shareholders receive only a small portion (e.g., $1-p=10 \%$ ) of the return. If, on the other hand, the asset returns are below $i$, then $100 \%$ of the shortfall has to be compensated by the shareholder. Additionally, if the insurer distributes a high surplus, this increases the insurer's future risk since the rate $i$ has to be credited also to this surplus amount in subsequent years. Such products constitute a significant

\footnotetext{
${ }^{5}$ For the equivalence principle, see e.g., Saxer [25], Wolthuis [28].
} 

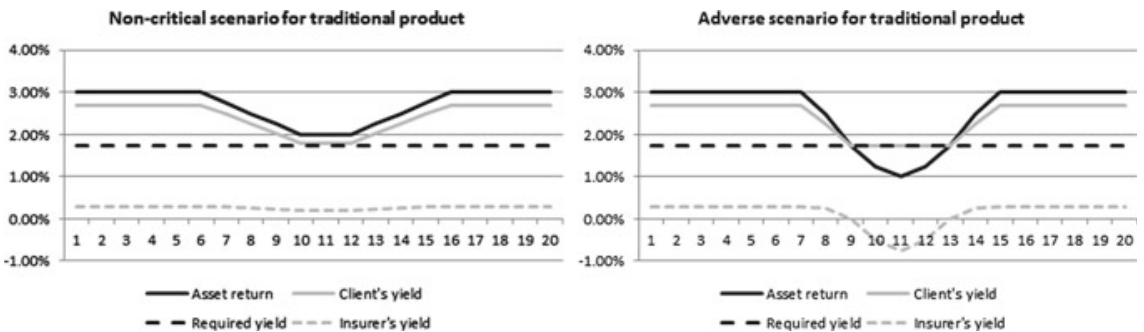

Fig. 1 Two illustrative deterministic scenarios for the traditional product: asset returns and yield distribution

financial risk to the insurance company, in particular in a framework of low interest rates and volatile capital markets. ${ }^{6}$

The mechanics of this year-to-year guarantee are illustrated in Fig. 1 for two illustrative deterministic scenarios. We consider a traditional policy with term to maturity $T=20$ years and a guaranteed benefit of $G=€ 20,000$. Following the current situation in Germany, we let $i=1.75 \%$ and assume a surplus participation rate of $p=90 \%$ on the asset returns.

The first scenario is not critical for the insurer. The asset return (which is here arbitrarily assumed for illustrative purposes) starts at $3 \%$, then over time drops to $2 \%$ and increases back to $3 \%$ where the $\mathrm{x}$ axis shows the policy year. The chart shows this asset return, the "client's yield" (i.e., the interest credited to the client's account including surplus), the "required yield" (which is defined as the minimum rate that has to be credited to the client's account), and the insurer's yield (which is the portion of the surplus that goes to the shareholder). Obviously, in this simple example, the client's yield always amounts to $90 \%$ of the asset return and the insurer's yield always amounts to $10 \%$ of the asset return. By definition, for this contract design, the required yield is constant and always coincides with $i=1.75 \%$.

In the second scenario, we let the asset return drop all the way down to $1 \%$. Whenever $90 \%$ of the asset return would be less than the required yield, the insurer has to credit the required yield to the account value. This happens at the shareholder's expense, i.e., the insurer's yield is reduced and even becomes negative. This means that a shortfall occurs and the insurer has to provide additional funds.

It is worthwhile noting that in this traditional product design, the interest rate $i$ plays three different roles:

- pricing interest rate $i_{p}$ used for determining the ratio between the premium and the guaranteed maturity benefit,

- reserving interest rate $i_{r}$, i.e., technical interest rate used for the calculation of the prospective actuarial reserves,

- year-to-year minimum guaranteed interest rate $i_{g}$, i.e., a minimum return on the account value.

${ }^{6}$ This was also a key result of the QIS5 final report preparing for Solvency II, cf. [2, 11]. 


\subsection{Alternative Products}

We will now introduce two alternative product designs, which are based on the idea to allow different values for the pricing rate, the reserving rate and the year-toyear minimum guaranteed interest rate on the account value. So Formulas 1 and 2 translate to the following formulae for the relation between the annual premium, the guaranteed benefit and the actuarial reserves:

$$
\begin{gathered}
\sum_{t=0}^{T-1}\left(P-c_{t}\right) \cdot\left(1+i_{p}\right)^{T-t}=G \\
A R_{t}=G \cdot\left(\frac{1}{1+i_{r}}\right)^{T-t}-\sum_{k=t}^{T-1}\left(P-c_{k}\right) \cdot\left(\frac{1}{1+i_{r}}\right)^{k-t} .
\end{gathered}
$$

Note, that in the first years of the contract, negative values for $A R_{t}$ are possible in case of $i_{p}<i_{r}$, which implies a "financial buffer" at the beginning of the contract. The year-to-year minimum guaranteed interest rate $i_{g}$ is not relevant for the formulae above, but it is simply a restriction for the development of the client's account, i.e.,

$$
A V_{t} \geq\left(A V_{t-1}+P-c_{t-1}\right) \cdot\left(1+i_{g}\right),
$$

where $A V_{0}=\max \left\{A R_{0}, 0\right\}$ is the initial account value of the contract.

The crucial difference between such new participating products and traditional participating products is that the guaranteed maturity benefit is not explicitly increased during the lifetime of the contract (but, of course, an increase in the account value combined with the year-to-year minimum guaranteed interest rate can implicitly increase the maturity guarantee).

In this setting, the prospective reserve $A R_{t}$ is only a minimum reserve for the guaranteed maturity benefit: The insurer has to make sure that the account value does not fall below this minimum reserve. This results in a "required yield" explained below. Under "normal" circumstances the account value (which is also the surrender value) exceeds the minimum reserve. Therefore, the technical reserve (under local GAAP), which may not be below the surrender value, coincides with the account value.

The required yield on the account value in year $t$ is equal to

$$
z_{t}=\max \left\{\frac{\max \left\{A R_{t}, 0\right\}}{A V_{t-1}+P-c_{t-1}}-1, i_{g}\right\} .
$$

The left part of (3) assures that the account value is nonnegative and never lower than the actuarial reserve. The required yield decreases if the bonus reserve (which is included in $A V_{t-1}$ ) increases. 
The surplus participation rules remain unchanged: the policyholder's share $p$ (e.g., $90 \%$ ) of the asset return is credited to the policyholders (but not less than $z_{t}$ ). Hence, as long as the policyholder's share is always above the technical interest rate used in the traditional product, there is no difference between the traditional and the alternative product designs.

Obviously, only combinations fulfilling $i_{g} \leq i_{p} \leq i_{r}$ result in suitable products: If the first inequality is violated, then the year-to-year minimum guaranteed interest rate results in a higher (implicitly) guaranteed maturity benefit than the (explicit) guarantee resulting from the pricing rate. If the second inequality is violated then at $t=0$, additional reserves (exceeding the first premium) are required.

In what follows, we will consider two concrete alternative contract designs. Obviously, the choice of $i_{g}$ fundamentally changes the mechanics of the guarantee embedded in the product (or the "type" of guarantee), whereas the choice of $i_{p}$ changes the level of the guarantee. Since the focus of this paper is on the effect of the different guarantee mechanisms, we use a pricing rate that coincides with the technical rate of the traditional product. Hence, the guaranteed maturity benefit remains unchanged. Since the legally prescribed maximum value for the reserving rate also coincides with the technical rate of the traditional product, we get $i_{p}=i_{r}=1.75 \%$ for both considered alternative designs.

In our alternative product 1 , we set $i_{g}=0 \%(0 \%$ year-to-year guarantee $)$ and for alternative 2 we set $i_{g}=-100 \%$ (no year-to-year guarantee). In order to illustrate the mechanics of the alternative products, Figs. 2 and 3 show the two scenarios from Fig. 1 for both alternative products. In the first scenario (shown on the left), the required yield $z_{t}$ on the account value gradually decreases for both alternative contract designs since the bonus reserve acts as some kind of buffer (as described above). For alternative 1, the required yield can of course not fall below $i_{g}=0 \%$, while for the alternative 2 it even becomes negative after some years.

The adverse scenario on the right shows that the required yield rises again after years with low asset returns since the buffer is reduced. However, contrary to the traditional product, the asset return stays above the required level and no shortfall occurs.
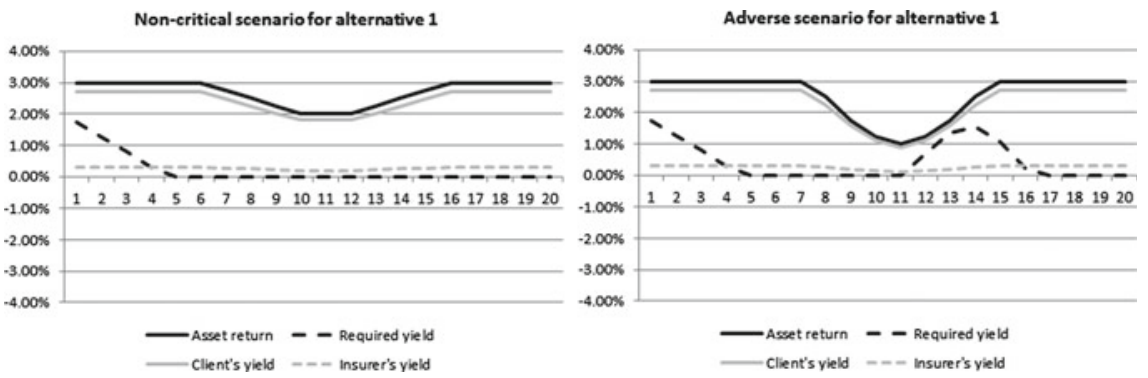

Fig. 2 Two illustrative deterministic scenarios for alternative 1 product: asset returns and yield distribution 


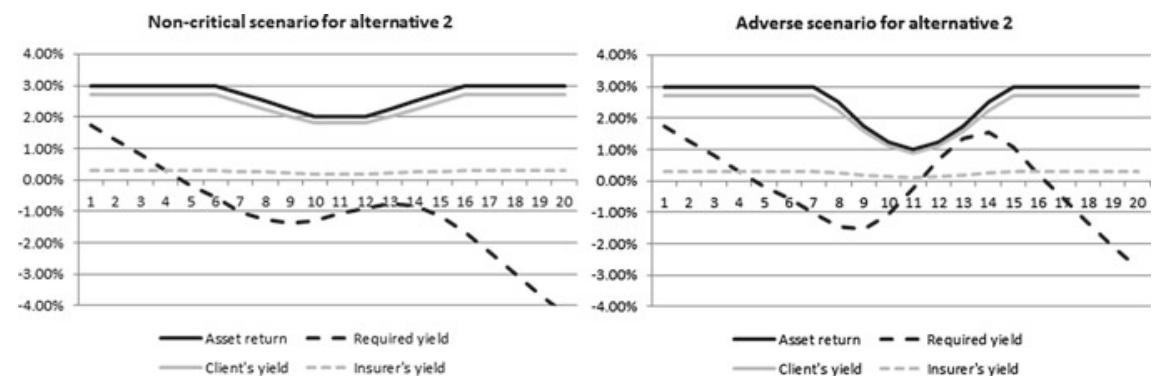

Fig. 3 Two illustrative deterministic scenarios for alternative 2 product: asset returns and yield distribution

From a policyholder's perspective, both alternative contract designs provide the same maturity benefit as the traditional contract design in the first scenario since the client's yield is always above $1.75 \%$. In the second scenario, however, the maturity benefit is slightly lower for both alternative contract designs since (part of) the buffer built up in years 1 to 8 can be used to avoid a shortfall. In this scenario, the two alternative products coincide, since the client's yield is always positive.

Even if scenarios where the products differ appear (or are) unlikely, the modification has a significant impact on the insurer's solvency requirements since the financial risks particularly in adverse scenarios are a key driver for the solvency capital requirement. This will be considered in a stochastic framework in the following sections.

\section{Stochastic Modeling and Analyzed Key Figures}

Since surplus participation is typically based on local GAAP book values (in particular in Continental Europe), we use a stochastic balance sheet and cash flow projection model for the analysis of the product designs presented in the previous section. The model includes management rules concerning asset allocation, reinvestment strategy, handling of unrealized gains and losses and surplus distribution. Since the focus of the paper is on the valuation of future profits and capital requirements we will introduce the model under a risk-neutral measure. Similar models have been used (also in a real-world framework) in Kling et al. [20, 21] and Graf et al. [16].

\subsection{The Financial Market Model}

We assume that the insurer's assets are invested in coupon bonds and stocks. We treat both assets as risky assets in a risk-neutral, frictionless and continuous financial 
market. Additionally, cash flows during the year are invested in a riskless bank account (until assets are reallocated). We let the short rate process $r_{t}$ follow a Vasicek ${ }^{7}$ model, and the stock price $S_{t}$ follow a geometric Brownian motion:

$$
\begin{aligned}
\mathrm{d} r_{t} & =\kappa\left(\theta-r_{t}\right) \mathrm{d} t+\sigma_{r} \mathrm{~d} W_{t}^{(1)} \text { and } \\
\frac{\mathrm{d} S_{t}}{S_{t}} & =r_{t} \mathrm{~d} t+\rho \sigma_{S} \mathrm{~d} W_{t}^{(1)}+\sqrt{1-\rho^{2}} \sigma_{S} \mathrm{~d} W_{t}^{(2)},
\end{aligned}
$$

where $W_{t}^{(1)}$ and $W_{t}^{(2)}$ each denote a Wiener process on some probability space $(\Omega, \mathscr{F}, \mathbb{F}, \mathbb{Q})$ with a risk-neutral measure $\mathbb{Q}$ and the natural filtration $\mathbb{F}=\mathscr{F}_{t}=$ $\sigma\left(\left(W_{s}^{(1)}, W_{s}^{(2)}\right), s<t\right)$. The parameters $\kappa, \theta, \sigma_{r}, \sigma_{S}$ and $\rho$ are deterministic and constant. For the purpose of performing Monte Carlo simulations, the stochastic differential equations can be solved to

$$
\begin{aligned}
& S_{t}=S_{t-1} \cdot \exp \left(\int_{t-1}^{t} r_{u} \mathrm{~d} u-\frac{\sigma_{S}^{2}}{2}+\int_{t-1}^{t} \rho \sigma_{S} \mathrm{~d} W_{u}^{(1)}+\int_{t-1}^{t} \sqrt{1-\rho^{2}} \sigma_{S} \mathrm{~d} W_{u}^{(2)}\right) \text { and } \\
& r_{t}=\mathrm{e}^{-\kappa} \cdot r_{t-1}+\theta\left(1-\mathrm{e}^{-\kappa}\right)+\int_{t-1}^{t} \sigma_{r} \cdot \mathrm{e}^{-\kappa(t-u)} \mathrm{d} W_{u}^{(1)},
\end{aligned}
$$

where $S_{0}=1$ and the initial short rate $r_{0}$ is a deterministic parameter. Then, the bank account is given by $B_{t}=\exp \left(\int_{0}^{t} r_{u} \mathrm{~d} u\right)$. It can be shown that the four (stochastic) integrals in the formulae above follow a joint normal distribution. ${ }^{8}$ Monte Carlo paths are calculated using random realizations of this multidimensional distribution. The discretely compounded yield curve at time $t$ is then given by ${ }^{9}$

$$
\begin{aligned}
& r_{t}(s)= \\
& \exp \left[\frac{1}{s}\left(\frac{1-\mathrm{e}^{-\kappa s}}{\kappa} r_{t}+\left(s-\frac{1-\mathrm{e}^{-\kappa s}}{\kappa}\right) \cdot\left(\theta-\frac{\sigma_{r}^{2}}{2 \kappa^{2}}\right)+\left(\frac{1-\mathrm{e}^{-\kappa s}}{\kappa}\right)^{2} \frac{\sigma_{r}^{2}}{4 \kappa}\right)\right]-1
\end{aligned}
$$

for any time $t$ and term $s>0$. Based on the yield curves, we calculate par yields that determine the coupon rates of the considered coupon bonds.

\footnotetext{
${ }^{7}$ Cf. [27].

${ }^{8}$ Cf. Zaglauer and Bauer [29]. A comprehensive explanation of this property is included in Bergmann [6].

${ }^{9}$ See Seyboth [26] as well as Branger and Schlag [7].
} 
Table 1 Balance sheet at time $t$

\begin{tabular}{l|l}
\hline Assets & Liabilities \\
\hline$B V_{t}^{S}$ & $X_{t}$ \\
\hline$B V_{t}^{B}$ & $A V_{t}$ \\
\hline
\end{tabular}

\subsection{The Asset-Liability Model}

The insurer's simplified balance sheet at time $t$ is given by Table 1. Since our analysis is performed for a specific portfolio of insurance contracts on a stand-alone basis, there is no explicit allowance for shareholders' equity or other reserves on the liability side. Rather, $X_{t}$ denotes the shareholders' profit or loss in year $t$, with corresponding cash flow at the beginning of the next year. Together with $A V_{t}$ as defined in Sect. 2, this constitutes the liability side of our balance sheet.

In our projection of the assets and insurance contracts, incoming cash flows (premium payments at the beginning of the year, coupon payments and repayment of nominal at the end of the year) and outgoing cash flows (expenses at the beginning of the year and benefit payments at the end of the year) occur. In each simulation path, cash flows occurring at the beginning of the year are invested in a bank account. At the end of the year, the market values of the stocks and coupon bonds are derived and the asset allocation is readjusted according to a rebalancing strategy with a constant stock ratio $q$ based on market values. Conversely, $(1-q)$ is invested in bonds and any money on the bank account is withdrawn and invested in the portfolio consisting of stocks and bonds.

If additional bonds need to be bought in the process of rebalancing, the corresponding amount is invested in coupon bonds yielding at par with term $M$. However, toward the end of the projection, when the insurance contracts' remaining term is less than $M$ years, we invest in bonds with a term that coincides with the longest remaining term of the insurance contracts. If bonds need to be sold, they are sold proportionally to the market values of the different bonds in the existing portfolio.

With respect to accounting, we use book-value accounting rules following German GAAP, which may result in unrealized gains or losses (UGL): Coupon bonds are considered as held to maturity and their book value $B V_{t}^{B}$ is always given by their nominal amounts (irrespective if the market value is higher or lower). In contrast, for the book value of the stocks $B V_{t}^{S}$, the insurer has some discretion.

Of course, interest rate movements as well as the rebalancing will cause fluctuations with respect to the UGL of bonds. Also, the rebalancing may lead to the realization of UGL of stocks. In addition, we assume an additional management rule with respect to UGL of stocks: We assume that the insurer wants to create rather stable book value returns (and hence surplus distributions) in order to signal stability to the market. We, therefore, assume that a ratio $d_{\text {pos }}$ of the UGL of stocks is realized annually if unrealized gains exist and a ratio $d_{\text {neg }}$ of the UGL is realized annually if unrealized losses exist. In particular, $d_{\text {neg }}=100 \%$ has to be chosen in a legal framework where unrealized losses on stocks are not possible. 
Based on this model, the total asset return on a book value basis can be calculated in each simulation path each year as the sum of coupon payments from bonds, interest payments on the bank account, and the realization of UGL. The split between policyholders and shareholders is driven by the minimum participation parameter $p$ explained in Sect.2. If the cumulative required yield on the account values of all policyholders is larger than this share, there is no surplus for the policyholders, and exactly the respective required yield $z_{t}$ is credited to every account. Otherwise, surplus is credited, which amounts to the difference between the policyholders' share of the asset return and the cumulative required yield. Following the typical practice, e.g., in Germany, we assume that this surplus is distributed among the policyholders such that all policyholders receive the same client's yield (defined by the required yield plus surplus rate), if possible. To achieve that, we apply an algorithm that sorts the accounts by required yield, i.e., $\left(z_{t}^{(1)}, \ldots, z_{t}^{(k)}\right), k \in \mathbb{N}$ in ascending order. First, all contracts receive their respective required yield. Then, the available surplus is distributed: Starting with the contract(s) with the lowest required yield $z_{t}^{(1)}$, the algorithm distributes the available surplus to all these contracts until the gap to the next required yield $z_{t}^{(2)}$ is filled. Then, all the contracts with a required yield lower or equal to $z_{t}^{(2)}$ receive an equal amount of (relative) surplus until the gap to $z_{t}^{(3)}$ is filled, etc. This is continued until the entire surplus is distributed. The result is that all contracts receive the same client's yield if this unique client's yield exceeds the required yield of all contracts. Otherwise, there exists a threshold $z^{*}$ such that all contracts with a required yield above $z^{*}$ receive exactly their required yield (and no surplus) and all contracts with a required yield below $z^{*}$ receive $z^{*}$ (i.e., they receive some surplus).

From this, the insurer's profit $X_{t}$ results as the difference between the total asset return and the amount credited to all policyholder accounts. If the profit is negative, a shortfall has occurred, which we assume to be compensated by a corresponding capital inflow (e.g., from the insurer's shareholders) at the beginning of the next year. ${ }^{10}$ Balance sheet and cash flows are projected over $\tau$ years until all policies that are in force at time zero have matured.

\subsection{Key Drivers for Capital Efficiency}

The term Capital Efficiency is frequently used in an intuitive sense, in particular among practitioners, to describe the feasibility, profitability, capital requirement, and riskiness of products under risk-based solvency frameworks. However, to the best of our knowledge, no formal definition of this term exists. Nevertheless, it seems obvious that capital requirement alone is not a suitable figure for managing a

\footnotetext{
${ }^{10}$ We do not consider the shareholders' default put option resulting from their limited liability, which is in line with both, Solvency II valuation standards and the Market Consistent Embedded Value framework (MCEV), cf. e.g., [5] or [10], Sect. 5.3.4.
} 
product portfolio from an insurer's perspective. Rather, capital requirement and the resulting cost of capital should be considered in relation to profitability.

Therefore, a suitable measure of Capital Efficiency could be some ratio of profitability and capital requirement, e.g., based on the distribution of the random variable

$$
\frac{\sum_{t=1}^{\tau} \frac{X_{t}}{B_{t}}}{\sum_{t=1}^{\tau} \frac{R C_{t-1} \cdot \operatorname{Co} C_{t}}{B_{t}}} .
$$

The numerator represents the present value of the insurer's future profits, whereas the denominator is equal to the present value of future cost of capital: $R C_{t}$ denotes the required capital at time $t$ under some risk-based solvency framework, i.e., the amount of shareholders' equity needed to support the business in force. The cost of capital is derived by applying the cost of capital rate $\operatorname{CoC}_{t}$ for year $t$ on the required capital at the beginning of this year. ${ }^{11}$ In practical applications, however, the distribution of this ratio might not be easy to calculate. Therefore, moments of this distribution, a separate analysis of (moments of) the numerator and the denominator or even just an analysis of key drivers for that ratio could create some insight.

In this spirit, we will use a Monte Carlo framework to calculate the following key figures using the model described above:

A typical market consistent measure for the insurer's profitability is the expected present value of future profits (PVFP), ${ }^{12}$ which corresponds to the expected value of the numerator in (4). The PVFP is estimated based on Monte Carlo simulations:

$$
\mathrm{PVFP}=\frac{1}{N} \sum_{n=1}^{N} \sum_{t=1}^{\tau} \frac{X_{t}^{(n)}}{B_{t}^{(n)}}=\frac{1}{N} \sum_{n=1}^{N} \operatorname{PVFP}^{(n)}
$$

where $N$ is the number of scenarios, $X_{t}^{(n)}$ denotes the insurer's profit/loss in year $t$ in scenario $n, B_{t}^{(n)}$ is the value of the bank account after $t$ years in scenario $n$, and hence $\operatorname{PVFP}^{(n)}$ is the present value of future profits in scenario $n$.

In addition, the degree of asymmetry of the shareholder's cash flows can be characterized by the distribution of $\operatorname{PVFP}^{(n)}$ over all scenarios ${ }^{13}$ and by the time value of options and guarantees (TVOG). Under the MCEV framework, ${ }^{14}$ the latter is defined by

$$
\mathrm{TVOG}=\mathrm{PVFP}_{C E}-\mathrm{PVFP}
$$

\footnotetext{
11 This approach is similar to the calculation of the cost of residual nonhedgeable risk as introduced in the MCEV Principles in [9], although $R C_{t}$ reflects the total capital requirement including hedgeable risks.

12 The concept of PVFP is introduced as part of the MCEV Principles in [9].

${ }^{13}$ Note that this is a distribution under the risk-neutral measure and has to be interpreted carefully. However, it can be useful for explaining differences between products regarding PVFP and TVOG. ${ }^{14}$ Cf. [9].
} 
Table 2 Product parameters I

\begin{tabular}{l|l|l|l}
\hline & Traditional Product (\%) & Alternative 1 (\%) & Alternative 2 (\%) \\
\hline$i_{p}, i_{r}$ & 1.75 & 1.75 & 1.75 \\
\hline$i_{g}$ & 1.75 & 0 & -100 \\
\hline
\end{tabular}

where $\operatorname{PVFP}_{C E}=\sum_{t=1}^{\tau} \frac{X_{t}^{(C E)}}{B_{t}^{(C E)}}$ is the present value of future profits in the so-called "certainty equivalent" (CE) scenario. This deterministic scenario reflects the expected development of the capital market under the risk-neutral measure. It can be derived from the initial yield curve $r_{0}(s)$ based on the assumption that all assets earn the forward rate implied by the initial yield curve. ${ }^{15}$ The TVOG is also used as an indicator for capital requirement under risk-based solvency frameworks.

Comparing the PVFP for two different interest rate levels-one that we call basic level and a significantly lower one that we call stress level-provides another important key figure for interest rate risk and capital requirements. In the standard formula ${ }^{16}$ of the Solvency II framework

$$
\Delta \mathrm{PVFP}=\mathrm{PVFP}(\text { basic })-\mathrm{PVFP}(\text { stress })
$$

determines the contribution of the respective product to the solvency capital requirement for interest rate risk $\left(\mathrm{SCR}_{i n t}\right)$. Therefore, we also focus on this figure which primarily drives the denominator in (4).

\section{Results}

\subsection{Assumptions}

The stochastic valuation model described in the previous section is applied to a portfolio of participating contracts. For simplicity, we assume that all policyholders are 40 years old at inception of the contract and mortality is based on the German standard mortality table (DAV 2008 T). We do not consider surrender. Furthermore, we assume annual charges $c_{t}$ that are typical in the German market consisting of annual administration charges $\beta \cdot P$ throughout the contract's lifetime, and acquisition charges $\alpha \cdot T \cdot P$, which are equally distributed over the first 5 years of the contract. Hence, $c_{t}=\beta \cdot P+\alpha \frac{T \cdot P}{5} \mathbb{1}_{t \in\{0, \ldots, 4\}}$. Furthermore, we assume that expenses coincide with the charges. Product parameters are given in Tables 2 and 3.

Stochastic projections are performed for a portfolio that was built up in the past 20 years (i.e., before $t=0$ ) based on 1,000 new policies per year. Hence, we have a

\footnotetext{
${ }^{15}$ Cf. Oechslin et al. [24].

${ }^{16}$ A description of the current version of the standard formula can be found in [12].
} 
Table 3 Product parameters II

\begin{tabular}{l|l|l|l|l}
\hline$G(€)$ & $T$ (years) & $P(€)$ & $\beta(\%)$ & $\alpha(\%)$ \\
\hline 20,000 & 20 & 896.89 & 3 & 4 \\
\hline
\end{tabular}

portfolio at the beginning of the projections with remaining time to maturity between 1 year and 19 years (i.e., $\tau=19$ years). ${ }^{17}$ For each contract, the account value at $t=0$ is derived from a projection in a deterministic scenario. In this deterministic scenario, we use a flat yield curve of $3.0 \%$ (consistent with the mean reversion parameter $\theta$ of the stochastic model after $t=0$ ), and parameters for management rules described below. In line with the valuation approach under Solvency II and MCEV, we do not consider new business.

The book value of the asset portfolio at $t=0$ coincides with the book value of liabilities. We assume a stock ratio of $q=5 \%$ with unrealized gains on stocks at $t=0$ equal to $10 \%$ of the book value of stocks. The coupon bond portfolio consists of bonds with a uniform coupon of $3.0 \%$ where the time to maturity is equally split between 1 year and $M=10$ years.

Capital market parameters for the basic and stress projections are shown in Table 4. The parameters $\kappa, \sigma_{r}, \sigma_{S}$ and $\rho$ are directly adopted from Graf et al. [16]. The parameters $\theta$ and $r_{0}$ are chosen such that they are more in line with the current low interest rate level. The capital market stress corresponds to an immediate drop of interest rates by 100 basis points.

The parameters for the management rules are given in Table 5 and are consistent with current regulation and practice in the German insurance market.

For all projections, the number of scenarios is $N=5,000$. Further analyses showed that this allows for a sufficiently precise estimation of the relevant figures. ${ }^{18}$

Table 4 Capital market parameters

\begin{tabular}{l|l|l|l|l|l|l}
\hline & $r_{0}(\%)$ & $\theta(\%)$ & $\kappa(\%)$ & $\sigma_{r}(\%)$ & $\sigma_{S}(\%)$ & $\rho(\%)$ \\
\hline Basic & 2.5 & 3.0 & 30.0 & 2.0 & 20.0 & 15.0 \\
\hline Stress & 1.5 & 2.0 & & & & \\
\hline
\end{tabular}

\footnotetext{
${ }^{17}$ Note that due to mortality before $t=0$, the number of contracts for the different remaining times to maturity is not the same.

${ }^{18}$ In order to reduce variance in the sample an antithetic path selection of the random numbers is applied, cf. e.g., Glasserman [15].
} 
Table 5 Parameters for management rules

\begin{tabular}{l|l|l|l|l}
\hline$q(\%)$ & $M$ (years) & $d_{\text {pos }}(\%)$ & $d_{\text {neg }}(\%)$ & $p(\%)$ \\
\hline 5 & 10 & 20 & 100 & 90 \\
\hline
\end{tabular}

\subsection{Comparison of Product Designs}

In Table 6, the PVFP and the TVOG for the base case are compared for the three products. All results are displayed as a percentage of the present value of future premium income from the portfolio. For alternative 1, the PVFP increases from 3.63 to $4.24 \%$, i.e., by 0.61 percentage points (pp), compared to the traditional contract design (which corresponds to a $17 \%$ increase of profitability). This means that this product with a "maturity only" guarantee and an additional guarantee that the account value will not decrease is, as expected, more profitable than the product with a traditional year-to-year (cliquet-style) guarantee. This difference is mainly caused by the different degree of asymmetry of the shareholders' cash flows which is characterized by the TVOG. Since PVFP $C E$ amounts to $4.26 \%$ for all products in the base case, the difference of TVOG between the traditional product and alternative 1 is also $0.61 \mathrm{pp}$. This corresponds to a TVOG reduction of more than $90 \%$ for alternative 1 , which shows that the risk resulting from the interest rate guarantee is much lower for the modified product.

Compared to this, the differences between alternative 1 and alternative 2 are almost negligible. The additional increase of the PVFP is only $0.01 \mathrm{pp}$, which is due to a slightly lower TVOG compared to alternative 1 . This shows that the fact that the account value may decrease in some years in alternative 2 does not provide a material additional risk reduction.

Additional insights can be obtained by analyzing the distribution of $\operatorname{PVFP}^{(n)}$ (see Fig. 4) ${ }^{19}$ : For the traditional contract design, the distribution is highly asymmetric with a strong left tail and a significant risk of negative shareholder cash flows (on a present value basis). In contrast, both alternative contract designs exhibit an almost symmetric distribution of shareholder cash flows which explains the low TVOG. Hence, the new products result in a significantly more stable profit perspective for the shareholders, while for the traditional product the shareholder is exposed to significantly higher shortfall risk.

Ultimately, the results described above can be traced back to differences in the required yield. While for the traditional product, by definition, the required yield always amounts to $1.75 \%$, it is equal to $0 \%$ in most scenarios for the alternative 1 product. Only in the most adverse scenarios, the required yield rises toward $1.75 \% .^{20}$ For the alternative 2 product, it is even frequently negative.

\footnotetext{
${ }^{19}$ Cf. Footnote 13.

${ }^{20}$ Note that here, the required yield in the first projection year reflects the financial buffer available for the considered portfolio of existing contracts at $t=0$. This is different from the illustrations in Sect. 2, which consider individual contracts from inception to maturity.
} 
Distribution of PVFP( $n)$ in base case

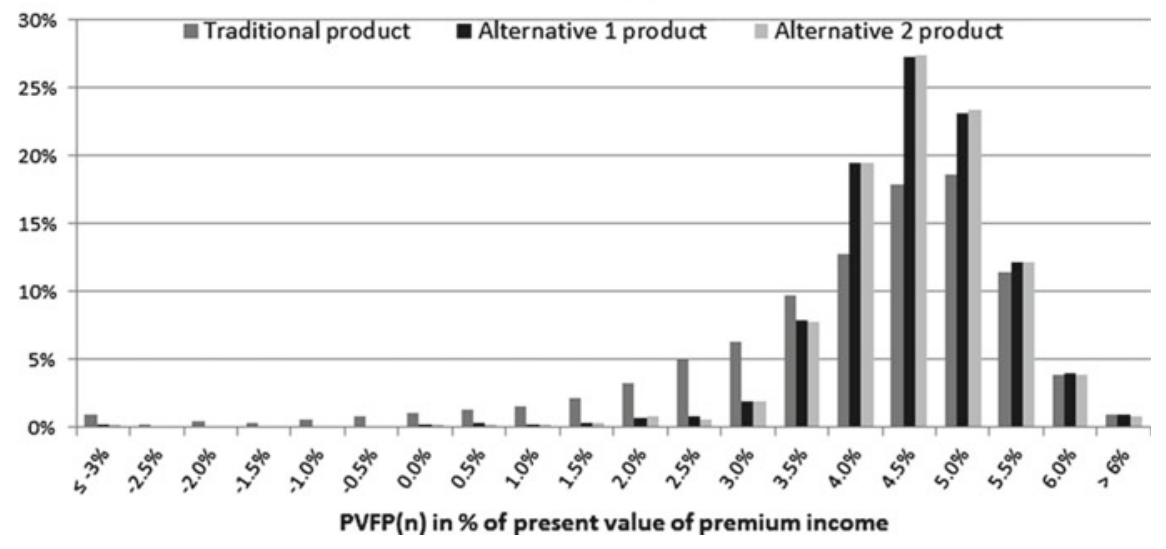

Fig. 4 Histogram of $\operatorname{PVFP}^{(n)}$ in base case

Table 6 PVFP and TVOG for base case (as percentage of the present value of premium income)

\begin{tabular}{l|l|l|l}
\hline & Traditional product $(\%)$ & Alternative 1 $(\%)$ & Alternative 2 $(\%)$ \\
\hline PVFP & 3.63 & 4.24 & 4.25 \\
\hline TVOG & 0.63 & 0.02 & 0.01 \\
\hline
\end{tabular}

Apart from the higher profitability, the alternative contract designs also result in a lower capital requirement for interest rate risk. This is illustrated in Table 7, which displays the PVFP under the interest rate stress and the difference to the basic level. Compared to the basic level, the PVFP for the traditional product decreases by $75 \%$, which corresponds to an $\mathrm{SCR}_{\text {int }}$ of $2.73 \%$ of the present value of future premium income. In contrast, the PVFP decreases by only around $40 \%$ for the alternative contract designs and thus the capital requirement is only 1.66 and $1.65 \%$, respectively.

We have seen that a change in the type of guarantee results in a significant increase of the PVFP. Further analyses show that a traditional product with guaranteed interest rate $i=0.9 \%$ instead of $1.75 \%$ would have the same PVFP (i.e., $4.25 \%$ ) as the alternative contract designs with $i_{p}=1.75 \%$. Hence, although changing only the type of guarantee and leaving the level of guarantee intact might be perceived as a rather small product modification by the policyholder, it has the same effect on the insurer's profitability as reducing the level of guarantee by a significant amount.

Furthermore, our results indicate that even in an adverse capital market situation the alternative product designs may still provide an acceptable level of profitability: The profitability of the modified products if interest rates were 50 basis points lower roughly coincides with the profitability of the traditional product in the base case. 
Table 7 PVFP for stress level and PVFP difference between basic and stress level

\begin{tabular}{l|l|l|l}
\hline & Traditional product $(\%)$ & Alternative 1 (\%) & Alternative 2 (\%) \\
\hline PVFP(basic) & 3.63 & 4.24 & 4.25 \\
\hline PVFP(stress) & 0.90 & 2.58 & 2.60 \\
\hline$\triangle$ PVFP & 2.73 & 1.66 & 1.65 \\
\hline
\end{tabular}

\subsection{Sensitivity Analyses}

In order to assess the robustness of the results presented in the previous section, we investigate three different sensitivities:

1. Interest rate sensitivity: The long-term average $\theta$ and initial rate $r_{0}$ in Table 4 are replaced by $\theta=2.0 \%, r_{0}=1.5 \%$ for the basic level, and $\theta=1.0 \%, r_{0}=0.5 \%$ for the stress level.

2. Stock ratio sensitivity: The stock ratio is set to $q=10 \%$ instead of $5 \%$.

3. Initial buffer sensitivity: The initial bonus reserve $B R_{t}=A V_{t}-A R_{t}$ is doubled for all contracts. ${ }^{21}$

The results are given in Table 8 .

Interest rate sensitivity If the assumed basic interest rate level is lowered by 100 basis points, the PVFP decreases and the TVOG increases significantly for all products. In particular, the alternative contract designs now also exhibit a significant TVOG. This shows that in an adverse capital market situation, also the guarantees embedded in the alternative contract designs can lead to a significant risk for the shareholder and an asymmetric distribution of profits as illustrated in Fig. 5. Nevertheless, the alternative contract designs are still much more profitable and less volatile than the traditional contract design and the changes in PVFP/TVOG are much less pronounced than for the traditional product: while the TVOG rises from 0.63 to $2.13 \%$, i.e., by $1.50 \mathrm{pp}$ for the traditional product, it rises by only $0.76 \mathrm{pp}$ (from 0.02 to $0.78 \%$ ) for alternative 1 .

As expected, an additional interest rate stress now results in a larger $\mathrm{SCR}_{\text {int }}$. For all product designs, the PVFP after stress is negative and the capital requirement increases significantly. However, as in the base case (cf. Table 7), the SCR $\mathrm{S}_{\text {int }}$ for the traditional product is more than one percentage point larger than for the new products.

Stock ratio sensitivity The stock ratio sensitivity also leads to a decrease of PVFP and an increase of TVOG for all products. Again, the effect on the PVFP of the traditional product is much stronger: The profit is about cut in half (from 3.63 to $1.80 \%$ ), while for the alternative 1 product the reduction is much smaller (from 4.24 to $3.83 \%$ ), and even smaller for alternative 2 (from 4.25 to $3.99 \%$ ). It is noteworthy that with a larger stock ratio of $q=10 \%$ the difference between the two alternative ${ }^{21}$ The initial book and market values of the assets are increased proportionally to cover this addi-
tional reserve. 
Table 8 PVFP, TVOG, PVFP under interest rate stress and $\triangle$ PVFP for base case and all sensitivities

\begin{tabular}{l|c|c|c}
\hline Base case & Traditional product $(\%)$ & Alternative 1 (\%) & Alternative 2 (\%) \\
\hline PVFP & 3.63 & 4.24 & 4.25 \\
\hline TVOG & 0.63 & 0.02 & 0.01 \\
\hline PVFP(stress) & 0.90 & 2.58 & 2.60 \\
\hline$\Delta$ PVFP & 2.73 & 1.66 & 1.65 \\
\hline Interest rate sensitivity & & & \\
\hline PVFP & 0.90 & 2.58 & 2.60 \\
\hline TVOG & 2.13 & 0.78 & 0.76 \\
\hline PVFP(stress) & -4.66 & -1.81 & -1.76 \\
\hline$\Delta$ PVFP & 5.56 & 4.39 & 4.36 \\
\hline Stock ratio sensitivity & & & \\
\hline PVFP & 1.80 & 3.83 & 3.99 \\
\hline TVOG & 2.45 & 0.43 & 0.26 \\
\hline PVFP(stress) & -1.43 & 1.65 & 1.92 \\
\hline$\Delta$ PVFP & 3.23 & 2.18 & 2.07 \\
\hline Initial buffer sensitivity & & & \\
\hline PVFP & 3.74 & 4.39 & 4.39 \\
\hline TVOG & 0.64 & $<0.01$ & $<0.01$ \\
\hline PVFP(stress) & 1.02 & 2.87 & 2.91 \\
\hline$\triangle P V F P$ & 2.72 & 1.52 & 1.48
\end{tabular}

products becomes more pronounced, which is reflected by the differences of the TVOG. Alternative 2 has a lower shortfall risk than alternative 1 since the account value may decrease in some years as long as the account value does not fall below the minimum reserve for the maturity guarantee. Hence, we can conclude that the guarantee that the account value may not decrease becomes more risky if asset returns exhibit a higher volatility.

The results for the stressed PVFPs under the stock ratio sensitivity are in line with these results: First, the traditional product requires even more solvency capital: The $\mathrm{SCR}_{\text {int }}$ is half a percentage point larger than in the base case (3.23\% compared to $2.73 \%$ ), and it is also more than one percentage point larger than for the alternative products with $10 \%$ stocks $(2.18 / 2.07 \%)$. Second, the interest rate stress shows a more substantial difference between the two different alternative products. While the difference of the $\mathrm{SCR}_{i n t}$ between alternative 1 and 2 was $0.01 \%$ in the base case, it is now $0.11 \%$.

Initial buffer sensitivity If the initial buffer is increased, we observe a slight increase of the PVFP for all products. However, there are remarkable differences for the effect on TVOG between the traditional and the alternative products: While for the traditional product the TVOG remains approximately the same, for the alternative products it is essentially reduced to zero. This strongly supports our product 
Distribution of PVFP(n) with interest rate sensitivity

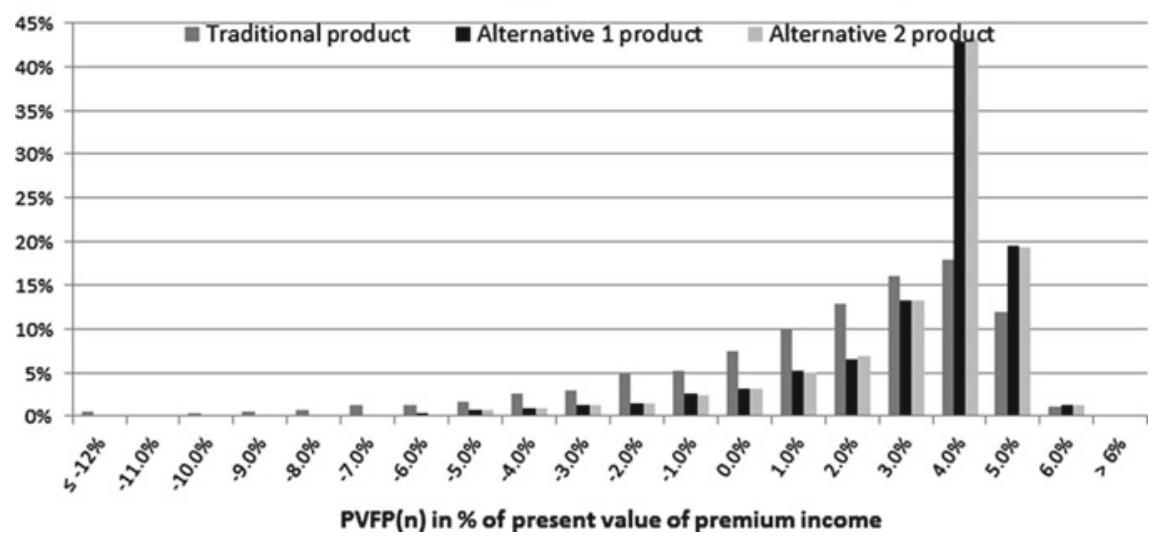

Fig. 5 Histogram of $\operatorname{PVFP}^{(n)}$ for interest rate sensitivity ( -100 basis points)

motivation in Sect. 2: For the alternative products, larger surpluses from previous years reduce risk in future years. ${ }^{22}$ Furthermore, the stressed PVFPs imply that the decrease of capital requirement is significantly larger for the alternative products: $0.14 \%$ reduction (from 1.66 to $1.52 \%$ ) for alternative 1 and $0.17 \%$ reduction (from 1.65 to $1.48 \%$ ) for alternative 2 , compared to just $0.01 \%$ reduction for the traditional product.

\subsection{Reduction in the Level of Guarantee}

So far we have only considered contracts with a different type of guarantee. We will now analyze contracts with a lower level of guarantee, i.e., products where $i_{p}<i_{r}$. If we apply a pricing rate of $i_{p}=1.25 \%$ instead of $1.75 \%$, the annual premium required to achieve the same guaranteed maturity benefit rises by approx. $5.4 \%$, which results in an additional initial buffer for this contract design. For the sake of comparison, we also calculate the results for the traditional product with a lower guaranteed interest rate $i=1.25 \%$. The respective portfolios at $t=0$ are derived using the assumptions described in Sect. 4.1.

The results are presented in Table 9. We can see that the PVFP is further increased and the TVOG is very close to 0 for the modified alternative products, which implies an almost symmetric distribution of the PVFP. The TVOG can even become slightly negative due to the additional buffer in all scenarios. Although the risk situation for the traditional product is also improved significantly due to the lower guarantee, the

\footnotetext{
${ }^{22}$ From this, we can conclude that if such alternative products had been sold in the past, the risk situation of the life insurance industry would be significantly better today in spite of the rather high nominal maturity guarantees for products sold in the past.
} 
Table 9 PVFP, TVOG, PVFP under interest rate stress and $\triangle$ PVFP for the alternative products with lower pricing rate

\begin{tabular}{l|l|l|l|l|c|c}
\hline & $\begin{array}{l}\text { Traditional } \\
\text { product }(\%)\end{array}$ & $\begin{array}{l}\text { Alternative } \\
1(\%)\end{array}$ & $\begin{array}{l}\text { Alternative } \\
2(\%)\end{array}$ & $\begin{array}{l}\text { Traditional } \\
i=1.25(\%)\end{array}$ & $\begin{array}{l}\text { Alternative 1 } \\
i_{p}=1.25(\%)\end{array}$ & $\begin{array}{l}\text { Alternative 2 } \\
i_{p}=1.25(\%)\end{array}$ \\
\hline PVFP & 3.63 & 4.24 & 4.25 & 4.12 & 4.31 & 4.31 \\
\hline TVOG & 0.63 & 0.02 & 0.01 & 0.14 & -0.05 & -0.05 \\
\hline $\begin{array}{l}\text { PVFP } \\
\text { (stress) }\end{array}$ & 0.90 & 2.58 & 2.60 & 2.43 & 3.28 & 3.32 \\
\hline$\triangle$ PVFP & 2.73 & 1.66 & 1.65 & 1.69 & 1.03 & 0.99 \\
\hline
\end{tabular}

alternative products can still preserve their advantages. A more remarkable effect can be seen for the $\mathrm{SCR}_{\text {int }}$, which amounts to 1.03 and $0.99 \%$ for the alternative products 1 and 2 , respectively, compared to $1.69 \%$ for the traditional product. Hence, the buffer leads to a significant additional reduction of solvency capital requirements for the alternative products meaning that these are less affected by interest rate risk.

\section{Conclusion and Outlook}

In this paper, we have analyzed different product designs for traditional participating life insurance contracts with a guaranteed maturity benefit. A particular focus of our analysis was on the impact of product design on capital requirements under risk-based solvency frameworks such as Solvency II and on the insurer's profitability.

We have performed a market consistent valuation of the different products and have analyzed the key drivers of Capital Efficiency, particularly the value of the embedded options and guarantees and the insurer's profitability.

As expected, our results confirm that products with a typical year-to-year guarantee are rather risky for the insurer, and hence result in a rather high capital requirement. Our proposed product modifications significantly enhance Capital Efficiency, reduce the insurer's risk, and increase profitability. Although the design of the modified products makes sure that the policyholder receives less than with the traditional product only in extreme scenarios, these products still provide a massive relief for the insurer since extreme scenarios drive the capital requirements under Solvency II and SST.

It is particularly noteworthy that starting from a standard product where the guaranteed maturity benefit is based on an interest rate of $1.75 \%$, changing the type of the guarantee to our modified products (but leaving the level of guarantee intact) has the same impact on profitability as reducing the level of guarantee to an interest rate of $0.9 \%$ and not modifying the type of guarantee. Furthermore, it is remarkable that the reduction of $\mathrm{SCR}_{\text {int }}$ from the traditional to the alternative contract design is very robust throughout our base case as well as all sensitivities and always amounts to slightly above one percentage point. 
We would like to stress that the product design approach presented in this paper is not model arbitrage (hiding risks in "places the model cannot see"), but a real reduction of economic risks. In our opinion, such concepts can be highly relevant in practice if modified products keep the product features that are perceived and desired by the policyholder, preserve the benefits of intertemporal risk sharing, and do away with those options and guarantees of which policyholders often do not even know they exist. Similar modifications are also possible for many other old age provision products like dynamic hybrid products ${ }^{23}$ or annuity payout products. Therefore, we expect that the importance of "risk management by product design" will increase. This is particularly the case since-whenever the same pool of assets is used to back new and old products - new capital efficient products might even help reduce the risk resulting from an "old" book of business by reducing the required yield of the pool of assets.

We, therefore, feel that there is room for additional research: It would be interesting to analyze similar product modifications for the annuity payout phase. Also-since many insurers have sold the traditional product in the past - an analysis of a change in new business strategy might be worthwhile: How would an insurer's risk and profitability change and how would the modified products interact with the existing business if the insurer has an existing (traditional) book of business in place and starts selling modified products today?

Another interesting question is how the insurer's optimal strategic asset allocation changes if modified products are being sold: If typical criteria for determining an optimal asset allocation are given (e.g., maximizing profitability under the restriction that some shortfall probability or expected shortfall is not exceeded), then the c.p. lower risk of the modified products might allow for a more risky asset allocation, and hence also higher expected profitability for the insurer and higher expected surplus for the policyholder. So, if this dimension is also considered, the policyholder would be compensated for the fact that he receives a weaker type of guarantee.

Finally, our analysis so far has disregarded the demand side. If some insurers keep selling the traditional product type, there should be little demand for the alternative product designs with reduced guarantees unless they provide some additional benefits. Therefore, the insurer might share the reduced cost of capital with the policyholder, also resulting in higher expected benefits in the alternative product designs.

Since traditional participating life insurance products play a major role in old-age provision in many countries and since these products have come under strong pressure in the current interest environment and under risk-based solvency frameworks, the concept of Capital Efficiency and the analysis of different product designs should be of high significance for insurers, researchers, and regulators to identify sustainable life insurance products. In particular, we would hope that legislators and regulators would embrace sustainable product designs where the insurer's risk is significantly reduced, but key product features as perceived and requested by policyholders are still present.

${ }^{23}$ Cf. Kochanski and Karnarski [22]. 
Open Access This chapter is distributed under the terms of the Creative Commons Attribution Noncommercial License, which permits any noncommercial use, distribution, and reproduction in any medium, provided the original author(s) and source are credited.

\section{References}

1. Allianz. Presentation Allianz Capital Markets Day, 2013. Available at https://www.allianz. com/v_1372138505000/media/investor_relations/en/conferences/capital_markets_days/ documents/2013_allianz_cmd.pdf

2. BaFin. Ergebnisse der fünften quantitativen Auswirkungsstudie zu Solvency II (QIS 5), 2011. Available at http://www.bafin.de/SharedDocs/Downloads/DE/Versicherer_Pensionsfonds/ QIS/dl_qis5_ergebnisse_bericht_bafin.pdf?_blob=publicationFile\&v=8

3. Barbarin, J., Devolder, P.: Risk measure and fair valuation of an investment guarantee in life insurance. Insur.: Math. Econ. 37(2), 297-323 (2005)

4. Bauer, D., Kiesel, R., Kling, A., Ruß, J.: Risk-neutral valuation of participating life insurance contracts. Insur.: Math. Econ. 39(2), 171-183 (2006)

5. Bauer, D., Reuß, A., Singer, D.: On the calculation of solvency capital requirement based on nested simulations. ASTIN Bull. 42(2), 453-499 (2012)

6. Bergmann, D.: Nested Simulations in Life Insurance. PhD thesis, University of Ulm (2011)

7. Branger, N., Schlag, C.: Zinsderivate. Modelle und Bewertung, Berlin (2004)

8. Briys, E., de Varenne, F.: On the risk of insurance liabilities: debunking some common pitfalls. J. Risk Insur. 64(4), 637-694 (1997)

9. CFO-Forum. Market Consistent Embedded Value Principles, 2009. Available at http://www. cfoforum.nl/downloads/MCEV_Principles_and_Guidance_October_2009.pdf

10. DAV. DAV Fachgrundsatz zum Market Consistent Embedded Value. Köln (2011)

11. EIOPA. EIOPA Report on the fifth Quantitative Impact Study (QIS5) for Solvency II, 2011. Available at http://eiopa.europa.eu/fileadmin/tx_dam/files/publications/reports/QIS5_ Report_Final.pdf

12. EIOPA. Technical Specifications on the Long Term Guarantee Assessment, 2013. Available at https://eiopa.europa.eu/consultations/qis/insurance/long-term-guarantees-assessment/ technical-specifications/index.html

13. Gatzert, N.: Asset management and surplus distribution strategies in life insurance: an examination with respect to risk pricing and risk measurement. Insur.: Math. Econ. 42(2), 839-849 (2008)

14. Gatzert, N., Kling, A.: Analysis of participating life insurance contracts: a unification approach. J. Risk Insur. 74(3), 547-570 (2007)

15. Glasserman, P.: Monte Carlo Methods in Financial Engineering. Springer, New York (1994)

16. Graf, S., Kling, A., Ruß, J.: Risk analysis and valuation of life insurance contracts: combining actuarial and financial approaches. Insur.: Math. Econ. 49(1), 115-125 (2011)

17. Grosen, A., Jorgensen, P.: Fair valuation of life insurance liabilities: the impact of interest rate guarantees, surrender options, and bonus policies. Insur.: Math. Econ. 26(1), 37-57 (2000)

18. Grosen, A., Jorgensen, P.: Life insurance liabilities at market value: an analysis of insolvency risk, bonus policy, and regulatory intervention rules in a barrier option framework. J. Risk Insur. 69(1), 63-91 (2002)

19. Grosen, A., Jensen, B., Jorgensen, P.: A finite difference approach to the valuation of path dependent life insurance liabilities. Geneva Pap. Risk Insur. Theory 26, 57-84 (2001)

20. Kling, A., Richter, A., Ruß, J.: The impact of surplus distribution on the risk exposure of with profit life insurance policies including interest rate guarantees. J. Risk Insur. 74(3), 571-589 (2007)

21. Kling, A., Richter, A., Ruß, J.: The interaction of guarantees, surplus distribution, and asset allocation in with-profit life insurance policies. Insur.: Math. Econ. 40(1), 164-178 (2007) 
22. Kochanski, M., Karnarski, B.: Solvency capital requirement for hybrid products. Eur. Actuar. J. 1(2), 173-198 (2011)

23. Mitersen, K., Persson, S.-A.: Guaranteed investment contracts: distributed and undistributed excess return. Scand. Actuar. J. 103(4), 257-279 (2003)

24. Oechslin, J., Aubry, O., Aellig, M.: Replicating embedded options. Life Pensions pp. 47-52 (2007)

25. Saxer, W.: Versicherungsmathematik. Springer, Berlin (1955)

26. Seyboth, M.: Der Market Consistent Appraisal Value und seine Anwendung im Rahmen der wertorientierten Steuerung von Lebensversicherungsunternehmen. $\mathrm{PhD}$ thesis, University of $\operatorname{Ulm}(2011)$

27. Vasicek, O.: An equilibrium characterization of the term structure. J. Financ. Econ. 5(2), 177188 (1977)

28. Wolthuis, H.: Life Insurance Mathematics. CAIRE, Brussels (1994)

29. Zaglauer, K., Bauer, D.: Risk-neutral valuation of participating life insurance contracts in a stochastic interest rate environment. Insur.: Math. Econ. 43(1), 29-40 (2008) 